\title{
AS ESTRATÉgIAS OPERATÓRIAS E A GESTÃO DA INFORMAÇÃO NO TRABALHO DE ENFERMAGEM, NO CONTEXTO HOSPITALAR
}

\author{
Diana Lúcia Moura Pinho ${ }^{1}$ \\ Julia Issy Abrahão ${ }^{2}$ \\ Mário César Ferreira ${ }^{2}$
}

Pinho DLM, Abrahão JI, Ferreira MC. As estratégias operatórias e a gestão da informação no trabalho de enfermagem, no contexto hospitalar. Rev Latino-am Enfermagem 2003 março-abril; 11(2):168-76.

O estudo analisa as estratégias operatórias de gestão da informação, utilizadas pelos enfermeiros no contexto hospitalar para regular o trabalho. O quadro teórico inscreve-se no campo da ergonomia, articulando conceitos de regulação da atividade, representações para e na ação. A Análise Ergonômica do Trabalho - AET orientou a coleta de dados. Os resultados demonstram que as estratégias adotadas pelos enfermeiros apóiam-se na utilização de um recurso informal externo (anotações pessoais) que visa, sobretudo, reduzir a carga mental de trabalho e garantir a fiabilidade de suas ações.

DESCRITORES: ergonomia (saúde ambiental), enfermagem

\section{THE OPERATORY STRATEGIES AND INFORMATION PROCESS OF THE NURSING WORK IN HOSPITAL CONTEXT}

The paper examines the relationship between operatory strategies and information process used by nurses, in hospital context, in order to regulate their ongoing activities. As a conceptual framework, a cognitive ergonomics model was adopted, linking concepts of work regulation and representation to action. The Ergonomics Work Analyses tool (EWA) was used to collect data. The results show that the cognitive strategies used by nurses, in the decision-making process, are based on their ongoing activities as in the preparation of personal notes, aiming, in particular, at reducing their mental workload and assuring the viability of their actions.

DESCRIPTORS: ergonomics (environmental health), nursing

\section{LAS ESTRATEGIAS OPERATÓRIAS Y LA GESTIÓN DE LA INFORMACIÓN DEL TRABAJO DE ENFERMEROS EN EL ENTORNO HOSPITALARIO}

El presente estudio investiga las estrategias operatorias en la gestión de la información utilizadas por los enfermeros, en el entorno hospitalario, para regular su trabajo. El cuadro teórico de referencia adoptado se incluye en el campo de la ergonomía articulando conceptos de conducta de regulación y representaciones para y en la acción. El "Análisis Ergonómico del Trabajo - AET "orientó la recolección de los datos. Los resultados demuestran que las estrategias cognitivas adoptadas por los enfermeros en la gestión de la información se apoya en la elaboración de anotaciones personales, con el objetivo, sobretodo, de reducir la carga de trabajo mental y garantizar la fiabilidad de sus acciones.

DESCRIPTORES: ergonomía (salud ambiental), enfermería

\footnotetext{
${ }^{1}$ Docente do Departamento de Enfermagem, Doutoranda do Programa de Pós-Graduação do Instituto de Psicologia, e-mail: diana@unb.br; ${ }^{2}$ Doutor em Ergonomia, Professor Adjunto do Instituto de Psicologia. Universidade de Brasília
} 
INTRODUÇÃO

$\boldsymbol{O}$ objetivo deste estudo em ergonomia é investigar a inter-relação entre as estratégias operatórias de gestão da informação e a regulação do trabalho de enfermagem no contexto hospitalar. O pressuposto subjacente à condução do estudo é que a informação constitui a base do processo decisório, subsidiando o planejamento, a execução e a avaliação das ações a serem desenvolvidas. Esse processo materializa a gestão da informação, cuja eficiência e eficácia solicitam dos sujeitos a construção de estratégias operatórias apropriadas para regulação da atividade, nas situações de trabalho que, muitas vezes, se apóiam no uso de instrumentos.

O contexto hospitalar apresenta certas especificidades no mundo do trabalho. Os hospitais congregam profissionais, saberes, tecnologias e infraestrutura diversificados. Sua configuração técnica e social é peculiar, caracterizada por uma divisão de trabalho extremamente precisa, bem como por diferentes modelos de ação profissional, sustentados nas competências, saberes e múltiplas estratégias dos profissionais. O funcionamento hospitalar é rico em processos produtivos altamente integrados, que se caracterizam: (a) por processos decisórios cujos níveis de complexidade variam; (b) por certa instabilidade do sistema; e (c) pela necessidade de uma articulação eficiente e rápida de diferentes profissionais para garantir a qualidade dos serviços prestados ${ }^{(1)}$.

Estudos mostram que a organização de trabalho hospitalar é marcada pelo particular ordenamento dos espaços físicos, pela singular padronização dos tempos quotidianos e pela estrutura rítmica da produção das atividades terapêuticas ${ }^{(1)}$. Essa produção está intimamente relacionada a uma rede de relações sociais, no seio da qual circulam informações pela via da comunicação oral (principalmente, a transmissão de relatório intra e interequipes) e escritas (do tipo registro documental e de rotinas administrativas), visando assegurar a continuidade da ação terapêutica. Estas informações são articuladas e geridas por estratégias diferenciadas, segundo a função do profissional, com vistas a atingir um objetivo comum: o atendimento ao paciente.

Assim, a gestão das informações no contexto hospitalar permeia a relação intra e interequipe como uma das formas de prevenir disfuncionamentos que podem trazer conseqüências irreversíveis à qualidade do atendimento. Os disfuncionamentos podem se manifestar sob diferentes formas, como, por exemplo: a troca de doentes, erros no preparo e administração de drogas e procedimentos inadequados à situação, podendo, nesses casos, repercutir no próprio estado de saúde do doente (atraso na recuperação, risco de vida) e, muitas vezes, com comprometimento do bem-estar dos profissionais envolvidos no trabalho hospitalar, assim como as implicações legais decorrentes, que podem repercutir na imagem institucional perante a sociedade. Ao gerir eventuais disfuncionamentos, o trabalhador modifica procedimentos, avalia alternativas e elabora soluções. Nessa perspectiva, a gestão da informação constitui um elemento essencial da fiabilidade do processo de trabalho hospitalar.

A compreensão da conduta adotada, pelos enfermeiros, para a gestão da informação, articula duas categorias teóricas complementares: (a) o conceito de regulação da atividade como mecanismo utilizado pelos sujeitos para responder às exigências de naturezas distintas no trabalho e a construção de representações para e na ação, que estruturam as estratégias cognitivas dos sujeitos ${ }^{(2-3)}$; e (b) o conceito psicológico de atividade instrumental $^{(4)}$.

O trabalho de enfermagem no contexto hospitalar

O processo de trabalho no setor de saúde apresenta algumas especificidades: ele se distingue do trabalho de outros setores da economia na medida que 0 seu produto final é um serviço resultante da ação compartilhada de vários profissionais e centra-se nas relações interpessoais entre beneficiários e executores; ele reúne um conjunto de atividades programadas e normatizadas que se realizam sob a base da cooperação em um cenário dinâmico e instável; as atividades podem ocorrer na forma de ações seqüenciais, isoladas ou na forma de histórias que representam o tratamento de um acontecimento em seu conjunto ${ }^{(5)}$. Apesar dessas especificidades e de sua importância para a vida da sociedade, a teorização é relativamente pequena. As pesquisas são numerosas e privilegiam o enfoque da etiologia das doenças e o tratamento dos agravos.

$\mathrm{Na}$ área de enfermagem, muitos estudos focalizam o mercado de trabalho, perfil dos profissionais e condições de trabalho ${ }^{(6-7)}$. O trabalho no contexto hospitalar e suas conseqüências para os enfermeiros são 
apresentados por alguns autores ${ }^{(5,8-9)}$. Esses autores salientam fatores que intensificam a carga de trabalho, ocasionando riscos para a saúde física e mental dos trabalhadores, como: a grande variedade de procedimentos realizados; o aumento constante do conhecimento teórico e prático exigido; a dificuldade no fluxo de informações; 0 ritmo de trabalho; o ambiente físico; o estresse; o contato com o doente e as vivências de dor e morte.

O custo psíquico do trabalho aparece estreitamente relacionado ao estado dos doentes, à necessidade de gerir os conflitos de prioridade e à complexa relação interpessoal a ser gerenciada pelos enfermeiros, visando atender às demandas dos doentes. Do ponto de vista cognitivo, o trabalho de enfermagem é fortemente influenciado: (a) pelo processo decisório que depende especialmente da comunicação em diversos níveis e que deve priorizar diferentes ações sob pressão temporal; (b) pela dinâmica e variabilidade das situações de trabalho; pela responsabilidade de acordo com o grau de autonomia; e (c) pela importância do conhecimento técnico e científico ${ }^{(5,10)}$. Nesse cenário, a gestão de informação é, portanto, um elemento essencial no sentido de garantir a fiabilidade no trabalho.

\section{A regulação da atividade}

A característica básica do comportamento humano em geral é que os próprios homens influenciam sua relação com o ambiente e, por meio deste, eles modificam o seu comportamento, colocando-o sob seu controle ${ }^{(11)}$. Nesse sentido, essa interação ocorre com base em um processo de regulação entre o sujeito, as propriedades do meio e os resultados da ação.

A regulação é um paradigma utilizado em diversos campos disciplinares e constitui um dos pilares teóricos da ergonomia. A eficiência, a eficácia e o bem-estar do sujeito no contexto de trabalho dependem fundamentalmente de sua capacidade de regulação com dupla finalidade: gerir as variações das condições externas e internas da atividade e controlar os seus efeitos. $\mathrm{O}$ uso dessa noção como parâmetro para explicar o mecanismo que estrutura a atividade não é recente em ergonomia ${ }^{(2)}$. "... cada trabalhador sente necessidade de regular sua própria produção. Ele mantém igualmente sua atividade em um nível satisfatório para si mesmo e para a organização. O grupo de operários também tende a prevenir o aumento localizado de cadências que conduziriam às reorganizações do sistema para reduzir os desequilíbrios".

Assim, o mecanismo de regulação que o sujeito adota, tem, por objetivo, não só obter o resultado a que se visa, mas também compensar ou prevenir os disfuncionamentos. Nesse sentido, o conceito de regulação em ergonomia pode ser entendido como uma articulação que o sujeito busca estabelecer, por meio da atividade, entre as exigências das tarefas, as condições postas, a evolução da situação, e com a dinâmica de seu estado interno. A regulação pode expressar-se de múltiplas formas, levando o sujeito a agir em feed-back ou no curso do processo de trabalho.

As representações para e na ação são definidas como: "processos mentais ativos de tomada de consciência e de apropriação das situações nas quais os indivíduos estão envolvidos e, ao mesmo tempo, são produtos, resultados de suas atividades" ${ }^{\prime 3)}$. Esses processos mentais operam-se de modo articulado sob a base de três mecanismos principais ${ }^{(12)}$ : (a) de memorização e evocação de conhecimentos; (b) de elaboração cognitiva, principalmente sob a forma de esquematizações, abstrações e simbolizações que permitem uma representação das situações específicas; e (c) de planificação e antecipação que possibilitam projetar a transformação das situações e estabelecer estratégias adequadas.

Essa abordagem tem suas raízes nos enfoques teóricos que sustentam a indissociabilidade entre conhecimento e ação, como a do paradigma da equilibração cognitiva, o qual enfatiza que, "dispondo de estruturas prontas para funcionar desde o nascimento, 0 sujeito age, de início, por assimilação das propriedades das coisas às estruturas psicológicas de que ele dispõe ou que lhe são disponíveis em um momento dado, toda resistência a esse processo de assimilação colocará, conseqüentemente, em questão tais estruturas psicológicas, obrigando-as a se modificarem, a se transformarem por acomodação, possibilitando uma nova assimilação; ou seja, a transpor a dificuldade posta por essa resistência. Dessa forma, pelo intermédio de sua atividade, pela qual observamos a busca permanente do equilíbrio entre as assimilações e as acomodações com os objetos da ação, o sujeito se autoconstrói, autotransforma-se, auto-regula-se e, nesse processo incessante, ele adquire sempre novos conhecimentos cada vez mais complexos" ${ }^{\text {"13). }}$.

Essas representações são operativas e finalísticas 
e desempenham uma função organizadora da atividade dos sujeitos. Colocá-las em evidência fornece elementos que permitem compreender como os sujeitos avaliam suas situações de trabalho, que objetivos eles estabelecem, como planificam suas ações e, principalmente, como eles constroem ou escolhem os meios para agir e controlar os efeitos da atividade.

A atividade de trabalho é indissociável de artefatos, tais como: instrumentos, signos, procedimentos, máquinas, métodos, leis, formas de organização do trabalho ${ }^{(4,14)}$. Assim, a análise da atividade requer a compreensão desses artefatos.

A atividade e o uso de instrumento em uma perspectiva psicológica

Os estudos e reflexões teóricas concernentes ao uso de instrumento no contexto de trabalho são numerosos na literatura, apontando pontos de convergência e identificação dos distintos papéis do instrumento, em relação à atividade dos sujeitos ${ }^{(4,15-16)}$. Em uma perspectiva psicológica, as propriedades características do instrumento são: (a) mediador que desempenha uma função de intermediação na relação estabelecida entre o sujeito e o objeto da ação; (b) meio para a ação, constitui para o sujeito um meio para sua atividade, facilitando sua interação com o mundo exterior; (c) operativo, cumpre uma função de ajuda ao sujeito, realizando uma parte de sua tarefa; e (d) cultural, expressa um meio de enriquecimento da experiência acumulada pela espécie humana.

No que concerne à função mediadora, o instrumento requer a compatibilidade entre as características do usuário e as propriedades do objeto da ação, podendo desempenhar duas funções complementares: mediação epistêmica (permite ao sujeito conhecer o objeto de sua ação), e mediação pragmática (permite ao sujeito transformar - no sentido amplo, incluindo controle e regulação - o objeto da ação). De acordo com a natureza da atividade, o instrumento pode ser: material (meio para transformação do objeto da ação); cognitivo (meio para a tomada de decisão); psicológico (meio para orientar a conduta); semiótico (meio para gerir as informações). Todo instrumento traz consigo elementos da cultura e da história, constituindo um modo de objetivação dos conhecimentos socialmente construídos ao longo de sua utilização.

O conceito psicológico de instrumento proposto por Rabardel funda-se na idéia de que o instrumento é uma entidade mista: de um lado, um artefato (material ou simbólico) produzido pelo sujeito ou por outros e, de outro, um ou vários esquemas mentais de utilização, construídos pelos sujeitos, de forma autônoma ou por meio da apropriação de algum já existente no contexto de trabalho, visando atender aos objetivos previstos pela organização ${ }^{(4)}$.

A utilização de instrumentos cognitivos requer a construção de representações mentais adequadas do processo em que estes se inscrevem e, regra geral, desempenha uma função de conhecimento (geralmente antecipador) dos objetos da realidade externa ao sujeito e sobre os quais sua atividade (de diagnóstico, de tomada de decisão, de transformação...) é dirigida.

\section{ABORDAGEM METODOLÓGICA}

O enfoque adotado foi a Análise Ergonômica do Trabalho (AET), de origem francofônica. Essa metodologia centrada em uma abordagem indutiva e na análise de situações reais de trabalho, constitui a base da ergonomia para compreender o trabalho e transformá-lo. A AET possibilita identificar as múltiplas exigências das tarefas e as estratégias adotadas pelos sujeitos para geri-las ${ }^{(17)}$.

A pesquisa realizou-se nas enfermarias do Serviço de Medicina [equivalente à "clinica médica" na prática hospitalar brasileira] de um hospital, integrado à rede pública do sistema de saúde de Portugal. Participaram do estudo oito enfermeiros que atuavam na área de prestação de cuidados e dispuseram-se a participar da pesquisa.

No primeiro momento, obteve-se a autorização do Conselho de Administração e da Comissão de Enfermagem da Instituição para a realização do estudo e, na seqüência, o projeto e os seus objetivos foram apresentados, por um dos autores, à chefia de enfermagem do serviço e aos sujeitos envolvidos, respeitando os princípios éticos que norteiam a pesquisa cientifica, visando obter a aprovação e planejar a realização da pesquisa, sem causar transtornos ao serviço.

A coleta de dados ocorreu em dois momentos. As fontes documentais [relatórios, manuais, formulários...], a observação direta e a entrevista semi-estruturada foram as técnicas utilizadas. Inicialmente, realizou-se a observação direta das atividades realizadas pelos enfermeiros, visando estabelecer uma maior aproximação 
com o campo e com os sujeitos, conhecer as situações de trabalho e identificar as situações características da gestão da informação. O registro das observações foi realizado em um diário de campo.

No segundo momento, realizaram-se as entrevistas, cuja finalidade foi evidenciar as representações dos sujeitos e apreender as estratégias cognitivas utilizadas na gestão da informação. Elaborou-se um roteiro de entrevista, comum a todos os enfermeiros, orientado pelas questões: $O$ que representa as anotações e o significado de cada uma delas? O significado da seqüência de organização? Como essas informações são utilizadas? Quais as informações transmitidas à equipe na passagem de plantão e com que objetivo? A partir desse guia, iamse aprofundando as informações, visando responder aos objetivos do estudo. Essas entrevistas foram realizadas individualmente, no local de trabalho, foram gravadas e transcritas, mediante consentimento dos enfermeiros e, posteriormente, o conteúdo foi validado pelos sujeitos do estudo.

O processo de análise do conteúdo das entrevistas foi realizado, com o auxilio do software Alceste (Análise Lexical por Contexto de um Conjunto de Segmentos de um Texto). Essa análise teve como objetivo identificar os elementos intrínsecos e extrínsecos das anotações pessoais, assim como analisar quantitativamente e qualitativamente o conteúdo, aprofundando a compreensão dos aspectos cognitivos do trabalho.

\section{RESULTADOS E DISCUSSÃO}

O Serviço tem capacidade para 43 leitos em diferentes especialidades da clínica médica. Ele funciona ininterruptamente, sob a responsabilidade de uma equipe de enfermagem, composta por 18 profissionais: um enfermeiro-chefe, dois enfermeiros especialistas ${ }^{*}$ e 15 enfermeiros graduados, distribuídos em três turnos de trabalho, segundo as necessidades do serviço. Os pacientes internados são procedentes dos serviços de ambulatório e de emergência.

O trabalho de enfermagem realizado é aquele previsto pela legislação do exercício profissional. Ele é centrado em três áreas de atuação correspondentes, respectivamente, à prestação de cuidados, à gestão e à assessoria técnica. A área de atuação da prestação de cuidados corresponde às categorias de enfermeiro, de enfermeiro graduado e de enfermeiro-especialista; enquanto a de gestão e a de assessoria técnica correspondem às categorias de enfermeiro-chefe, enfermeiro-supervisor e ao cargo de enfermeiro-diretor.

As situações de trabalho e a gestão da informação

São quatro situações de trabalho, distintas e interdependentes, que caracterizam a gestão da informação no contexto de trabalho e foram identificadas a partir da observação direta (Figura 1).

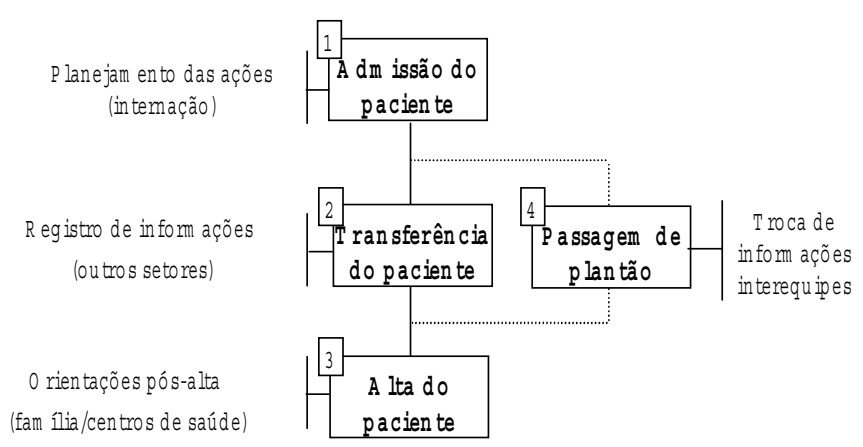

Figura 1 - Situações típicas de gestão da informação

Essas situações típicas do trabalho dos enfermeiros demandam exigências: físicas (gestual, postural), para o manuseio de equipamentos, materiais e instrumentos e, sobretudo, para cuidar do doente; cognitivas (gestão de informações, processo decisório), para gerir adequadamente as informações e responsabilidades que permeiam as diferentes tarefas; $\mathrm{e}$ psíquicas (comunicação, cooperação, relações hierárquicas), para responder às necessidades das relações sociais de trabalho e de sua organização. Tais exigências caracterizam as atividades dos enfermeiros, que devem responder quotidianamente a esses componentes da carga de trabalho.

A situação analisada

A gestão da informação apresenta-se com maior relevância, na situação de passagem de plantão, que ocorre três vezes ao dia. Trata-se de um momento em que os enfermeiros que encerram a sua jornada de trabalho

\footnotetext{
* Nesta categoria estão os enfermeiros habilitados com curso de especialização em uma área de enfermagem ou equivalentes
} 
repassam aos colegas, com a ajuda dos prontuários, uma atualização das ações efetuadas no turno e as orientações de ações futuras. Essas informações são essenciais para a manutenção e continuidade do atendimento aos doentes e constituir-se-ão em parâmetros norteadores para que o enfermeiro planeje suas ações e estruture sua estratégia operatória global na jornada que se inicia.

A passagem de plantão constitui, portanto, um momento privilegiado para a análise ergonômica das exigências cognitivas do trabalho, especialmente para compreender como os enfermeiros regulam suas atividades de gestão de informação para responder às exigências do trabalho. Assim, a escolha dessa situação para uma análise mais aprofundada foi em função: a) da freqüência da situação; b) da interação entre os membros das equipes trabalho; e c) do papel que as informações representam nessa situação para a construção das estratégias operatórias dos enfermeiros que iniciam a jornada.

Os três turnos estabelecidos pela organização do trabalho ocorrem diariamente às 8,14 e 20 horas, respectivamente. Para operacionalizar a passagem de turno e prevenir disfuncionamentos, ocorre uma superposição de 30 minutos que são utilizados para a gestão de informações interequipes. Um conjunto de procedimentos habituais caracteriza o "ritual" de passagem de plantão entre os enfermeiros: a) os enfermeiros relatam as informações de cada paciente, seguindo a ordem seqüencial de leitos; b) cada enfermeiro informa à nova equipe os pacientes que ficaram sob sua responsabilidade, orientando-se pelos registros efetuados no prontuário; c) o informe de cada enfermeiro pode ser mais ou menos detalhado em função dos questionamentos dos colegas e da situação do paciente; d) o relato informativo do enfermeiro sobre o paciente segue uma estrutura narrativa habitual: 1) número do leito e nome do paciente; condições gerais do paciente (estado de consciência, intercorrências, controles); 2) intervenções e procedimentos clínicos realizados; 3) reações do paciente; 4) procedimentos previstos para a continuidade do tratamento do paciente; e) caso se trate de novo paciente ou de algum que o enfermeiro não conheça, o relato é ampliado com informações relativas ao diagnóstico, às condições de admissão e ao planejamento dos cuidados necessários durante o período de internação.

Assim, a passagem de plantão constitui uma situação com peso hierárquico significativo na jornada de trabalho dos enfermeiros, à medida que ela: a) tem um papel estratégico para dar continuidade ao tratamento dos pacientes; b) caracteriza-se por um conjunto de informações complexas em função da diversidade de dados a serem tratados (estado do paciente, procedimentos, orientações, etc.) e da quantidade de pacientes; e c) depende da interação social do trabalho interequipes onde a comunicação deve ser estabelecida. Nesse sentido, a passagem de plantão obedece a règles de métier estritas, posto que um erro pode comprometer a qualidade do trabalho, a recuperação do paciente e, no limite, a vida deste.

A passagem de plantão dá visibilidade a uma situação efetiva de gestão individual e coletiva das informações necessárias à realização do trabalho de enfermagem, colocando em evidência uma das formas de gerir a informação no contexto hospitalar. Foi nesse contexto que se constatou a estratégia adotada pelos enfermeiros, na forma da utilização de anotações pessoais, quando iniciam o turno de trabalho.

O uso generalizado dessas anotações serviu como um indicador para a evolução da análise ergonômica, conduzindo-a para uma visão mais aprofundada do uso desse recurso pelos enfermeiros, a partir de três questões básicas: a) o que são essas anotações? b) que conteúdos do trabalho de enfermagem elas veiculam? c) qual a sua função e importância para a condução do trabalho dos enfermeiros? O contexto de trabalho encontrado subsidiou a elaboração da seguinte hipótese: para gerir as exigências do trabalho, os enfermeiros transformam suas anotações pessoais em um instrumento cognitivo que guia a definição de suas estratégias operatórias no processo de gestão da informação, visando garantir a eficiência e a eficácia do serviço realizado e reduzir o custo humano do trabalho.

\section{Características das anotações}

Para um estudo mais aprofundado das anotações pessoais habitualmente desprezadas no final da jornada, solicitou-se aos enfermeiros o acesso a essa fonte de informação, para uma análise em dois níveis: o intrínseco, referente às características internas de forma e conteúdo; e o extrínseco, relativo às características externas, da função (significado) para a atividade dos sujeitos. Desse modo, a AET possibilitou apreender a dimensão artefatual desse recurso e a sua função instrumental para a atividade dos enfermeiros. 
A dimensão artefatual das anotações pessoais

$\mathrm{Na}$ análise intrínseca do instrumento, constatouse um conjunto de aspectos que caracterizam a forma de apresentação e organização das informações. Eles se apresentam sob o formato de notas manuscritas (grafias singulares), caracteres alfanuméricos (diferenciados pelo uso de cores - vermelho e azul), símbolos e siglas. Essas informações respeitam uma organização espacial sistemática que orienta a distribuição do conteúdo, aparecendo, predominantemente, sob o formato de linhas.

Os dados demonstram que a organização dessas anotações não é casual, ao contrário, trata-se de uma "estruturação espacial" intencional que busca, sobretudo, facilitar o registro e a leitura das informações sobre os pacientes. Essa estruturação espacial das informações é construída com o intuito de facilitar a discriminação perceptiva dos dados e, dessa forma, otimizar sua operatividade nas situações de trabalho. Nesse sentido, dois segmentos da narrativa dos enfermeiros são ilustrativos: coloquei com uma cor diferente que é para depois me orientar; ou, ainda, é uma cor diferente, para quando eu for fazer as notas, eu não confundir com aquilo que eu já sabia. As verbalizações demonstram que esse é um recurso utilizado pelos enfermeiros para otimizar a gestão da informação face às exigências das situações.

Do ponto de vista de conteúdo, a apreensão dos diferentes tipos de registros permitiu compreender a função que essas anotações assumem no contexto da atividade dos enfermeiros. A Figura 2 apresenta um exemplo dos significados atribuídos pelos enfermeiros aos códigos usuais.

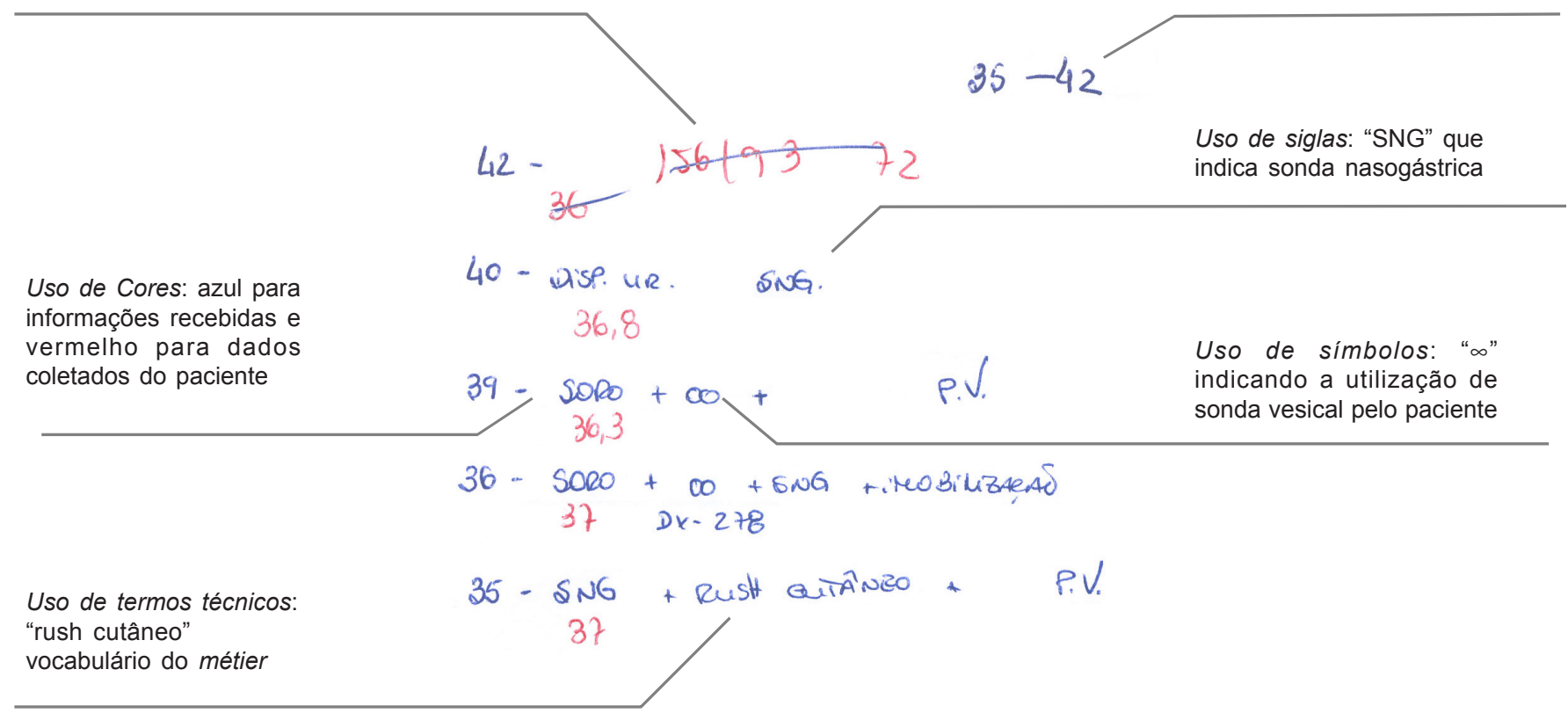

Figura 2 - Conteúdo e significados das anotações

As informações que "habitam as anotações" são portadoras de uma diversidade de significados que trazem, ao mesmo tempo, a marca da individualidade de cada enfermeiro e do coletivo de trabalho, em função da recorrência de registros de uso comum. Os modos de registros empregados e os estilos de descrição guardam traços de semelhança entre os membros das equipes. Entretanto, nas verbalizações, são freqüentes dados que ilustram os "estilos pessoais" de registros e significados particulares que o conteúdo assume: os dados em vermelho são precisos; este 8,5 foi a temperatura que registrei que o doente tinha, 8,5 e não 38,5 porque sei que 8 é depois do 30; se o doente foi admitido, no número da cama coloco um círculo envolvendo-o.

A análise do conteúdo do instrumento põe em evidência indicadores que revelam que a sua construção é resultante de um processo de "cognição compartilhada". Entretanto, o significado que assume cada anotação, mantém estreita interdependência com a sua função e com a importância que o conteúdo anotado no instrumento assume para o enfermeiro, no contexto real do trabalho ${ }^{(18)}$. 
O significado e a função instrumental

A análise das entrevistas, realizada com o auxilio do software Alceste, possibilitou um aprofundamento analítico sobre o significado e a funcionalidade das anotações pessoais dos enfermeiros. O uso desse software permitiu apreender as representações que os enfermeiros atribuem às anotações para as suas ações, evidenciando o seu caráter operativo no desempenho do trabalho. Essa análise indicou um conjunto de palavras cuja freqüência $\left(X^{2}>0,5\right)$ aponta a função estruturadora das verbalizações dos enfermeiros. $O$ indicador da função operativa para ação dos sujeitos expressa-se: 1) pela freqüência dos verbos (palavra-plena): avaliar, continuar, esquecer, fazer, ir, orientar, pôr, precisar, ser, ver e vigiar. Observa-se a existência de elementos que expressam "verbos de ação" e, desse modo, parecem revelar a indissociabilidade entre o uso das anotações e a atividade dos sujeitos; 2) pela freqüência dos verbetes (palavraferramenta): dia, doente, noite, ontem, quando, senhor. Nesse sentido, fornecem indícios tanto do "objeto" da ação dos enfermeiros [senhor, paciente], quanto de fatores temporais e situacionais [noite, ontem, dia, quando] e, desse modo, parecem dar visibilidade ao uso das anotações em relação às especificidades do contexto de trabalho.

Do ponto de vista qualitativo, a análise das palavras mais representativas nas verbalizações dos enfermeiros permitiu uma visão mais abrangente sobre o significado e a função do instrumento nas situações de trabalho. Nesse sentido, a função operativa do uso das anotações é representada por alguns eixos e coloca em evidência a sua importância para a ação dos sujeitos, sobretudo os diferentes significados que eles the atribuem, que não podem ser negligenciados para uma compreensão mais profunda da atividade desses profissionais.

\begin{tabular}{|c|c|}
\hline Operatividade & Exemplos de Verbalizações \\
\hline $\begin{array}{l}\text { Planejamento e } \\
\text { antecipação de } \\
\text { ações }\end{array}$ & $\begin{array}{l}\text { - isso [anotações] dá-nos uma pré-organização do nosso turno, por onde é que a gente há } \\
\text { de começar, o que é que havemos de fazer primeiro... } \\
\text { - por exemplo, o que eu escrevi hoje são as punções venosas porque sei que o doente vai } \\
\text { ter que ficar em jejum. }\end{array}$ \\
\hline $\begin{array}{l}\text { Diagnóstico do } \\
\text { estado do doente }\end{array}$ & $\begin{array}{l}\text { foi uma doente nova que entrou e eu preciso saber qual é a patologia, porque é que o } \\
\text { doente veio para o hospital, o motivo do internamento. } \\
\text { M.E. [anotação] significa 'mesmo estado'. É assim, porque eu tenho uma noção geral de } \\
\text { todos os doentes, sei como é que eles estão e o que é que me interessa saber, se eles } \\
\text { pioraram, se mantêm o mesmo estado. }\end{array}$ \\
\hline $\begin{array}{l}\text { Controle do } \\
\text { estado do doente }\end{array}$ & $\begin{array}{l}\text { anoto normalmente à tarde e à noite para vigiar a tensão arterial porque já não é por } \\
\text { rotina, são doentes hipertensos (...) eu ponho para vigiar a tensão. } \\
\text { O senhor da cama } 14(\ldots) \text { tem cateter mandrilado que está a fazer medicação, também se } \\
\text { deve vigiar. }\end{array}$ \\
\hline $\begin{array}{l}\text { Gestão do } \\
\text { trabalho em } \\
\text { equipe }\end{array}$ & $\begin{array}{l}\text { se um doente novo tem avc, eu vou avaliar se será para eu dar-lhe banho ou se pode ser } \\
\text { a empregada. } \\
\text { os doe não são doentes novos, eu e os meus colegas fazemos isso por hábito, primeiro vamos ver } \\
\text { não têm. }\end{array}$ \\
\hline Auxílio à memória & $\begin{array}{l}\text { normalmente, eu sublinho com vermelho, quando é mesmo importante, para não me } \\
\text { esquecer. } \\
\text { - para eu não me esquecer, quando eu der a minha voltinha para ver os doentes, já sei que } \\
\text { aquela doente tem um avc [acidente vascular cerebral] e diabetes. }\end{array}$ \\
\hline
\end{tabular}

Figura 3 - Operatividade das anotações nas verbalizações dos enfermeiros

A análise das verbalizações permitiu inferir que a gestão das informações, no trabalho de enfermagem, apóiase na construção de modos operatórios baseados no uso das anotações como instrumento cognitivo para a ação. Essa função instrumental das anotações, base das estratégias cognitivas, revela-se de diferentes formas: a) como um meio pelo qual o sujeito registra e trata informações diversas que são indispensáveis para gerir eficientemente as múltiplas exigências que caracterizam o trabalho de enfermagem; b) como um recurso externo informal - simples e eficaz - para gerenciar a complexidade das informações (estado do paciente, procedimentos, etc.), reduzindo a carga de trabalho mental (percepção e memória); c) como uma função mediadora na interação sujeito-meio, ajudando o enfermeiro a construir a sua representação da situação, definir o seu modo operatório, especialmente pelo diagnóstico, planejamento e controle das exigências do trabalho. 
Em síntese, pode-se afirmar que as anotações pessoais são as estratégias operatórias utilizadas pelos enfermeiros para gerir as diferentes informações simultaneamente. $\mathrm{O}$ uso dessas anotações contribui para o trabalho, agregando rapidez, fiabilidade e eficácia às suas ações.

A natureza instrumental das anotações aparece, no contexto específico, sob a modalidade de instrumento cognitivo. O caráter cognitivo reforça sua função de instrumento psicológico para a atividade dos enfermeiros à medida que as dimensões artefatual [papel] e representacional [anotações com cores distintas para orientar ações específicas] são evidentes. Nesse sentido, as anotações representam um instrumento de mediação, tanto epistêmico, pois possibilita ao enfermeiro conhecer o objeto de suas ações, quanto pragmático, por permitir o diagnóstico, a tomada de decisão, a execução e o controle sobre o estado dos doentes e os resultados de suas ações.

\section{CONCLUSÃO}

Resguardados os seus limites, o estudo coloca

\section{REFERÊNCIAS BIBLIOGRÁFICAS}

1. Carrapinheiro G. Saberes e poderes no hospital: uma sociologia dos serviços hospitalares. $2^{a}$ ed. Porto (Portugal): Afrontamento; 1993.

2. Faverge JM. L'analyse du travail en terme de régulation. In: Leplat J, coordinateur. L'analyse du travail en psychologie ergonomique. Toulouse (France): Éditions Octarés; 1992. p. 61-8.

3. Weill-Fassina A, Rabardel P, Dubois D. Représentations pour l'action. Toulouse (Françe): Octarés; 1993.

4. Rabardel P. Les hommes \& les technologies. Approche cognitive des instruments contemporains. Paris (France): Armand Colin; 1995.

5. Theureau J. Action et parole dans le travail infirmier. Psychologie Française 1983 dèc; 28 (3):255-64.

6. Pires D. Hegemonia médica na saúde e a enfermagem. São Paulo (SP): Cortez; 1989.

7. Almeida MCP, Rocha SMM, organizadoras. O trabalho de enfermagem. São Paulo (SP): Cortez; 1997.

8. Estryn-Behar M, Poinsignon $\mathrm{H}$. Travailler à l'hospital. Paris (France): Berger - Levrault; 1989.

9. Marziale MHP, Carvalho EC, Condições ergonômicas do trabalho da equipe de enfermagem em unidade de internação de cardiologia. Rev Latino-am Enfermagem 1998 janeiro; 6(1):99-117.

10. Matos DG. O trabalho do enfermeiro do centro cirúrgico: um estudo sob a ótica da ergonomia. [dissertação]. Brasília (DF): Instituto de Psicologia/UnB; 1994. em evidência: a gestão da informação no contexto hospitalar como elemento estruturante da atividade dos enfermeiros; a importância da dimensão cognitiva no processo de regulação da carga de trabalho; e a funcionalidade de uma das modalidades de regulação utilizada pelos enfermeiros. Demonstra a co-habitação de recursos formais e informais na regulação da atividade, para responder às exigências do trabalho.

A análise de natureza micro permitiu desvendar a presença de um recurso que, em outra abordagem metodológica, poderia passar despercebido. O recurso externo identificado assume a função de um instrumento de mediação não formalizado e, portanto, não apropriado à organização. Os resultados remetem à questão: poderse-iam modelizar os diferentes ciclos de regulação e os recursos que os enfermeiros utilizam com o intuito de minimizar sua carga de trabalho e assegurar a fiabilidade de suas ações?

Esses resultados reforçam a necessidade de compreender, em outros contextos, como os enfermeiros estabelecem a interface entre a dimensão individual e a coletiva, na gestão da informação, visando atender às exigências do trabalho.

11. Cole M, Jonh-Steiner V, Scribner S, Souberman E, organizadores. A formação social da mente: o desenvolvimento dos processos psicológicos superioresLS Vigotsky. $5^{\text {a }}$ ed. São Paulo (SP): Martins Fontes;1996.

12. Teiger C. L'approche ergonomique: du travail humain à l'activité des hommes et des femmes au travail. Education Permanente 1993; 116(3):71-96.

13. Dolle JM. Au-delà de Freud et Piaget. Jalons pour de nouvelles perspectives en Psychologie. Toulouse (France): Privat Editeur; 1987.

14. Wisner A. Aspects psychologiques de I' antrhroporechnologie. Le Travail Humain 1997; 60(3):22954.

15. Leontiev A. O desenvolvimento do psiquismo. São Paulo (SP): Editora Moraes; 1972.

16. Vygotsky LS. Teoria e método em psicologia. $2^{a}$ ed. São Paulo (SP): Martins Fontes; 1999.

17. Abrahão Jl. Ergonomia: modelo, métodos e técnicas. $2^{\circ}$ Congresso Latino-Americano e no $6^{\circ}$ Seminário Brasileiro de Ergonomia; 1993 Outubro; Florianópolis; Santa Catarina; 1993.

18. Ferreira MC, Weill-Fassina A. L'ordinateur dans le travail bancaire, un artefact producteur de béquilles cognitives? Actes du 9ème Congrès de l'Association Internationale de Psychologie du Travail de Langue Française. Québec; Canadá; 1996. 